\title{
The Meninges Is a Source of Retinoic Acid for the Late-Developing Hindbrain
}

\author{
Jinghua Zhang, ${ }^{1}$ Deborah Smith, ${ }^{1}$ Miyuki Yamamoto, ${ }^{3}$ Lanhua Ma, ${ }^{1}$ and Peter McCaffery ${ }^{1,2}$ \\ ${ }^{1}$ E. Kennedy Shriver Center and ${ }^{2}$ Department of Cell Biology, University of Massachusetts Medical School, University of Massachusetts, Waltham, \\ Massachusetts 02452, and ${ }^{3}$ Institute for Basic Medical Sciences, University of Tsukuba, Tsukuba, Ibaraki 305, Japan
}

\begin{abstract}
One general function for retinoic acid (RA) is pattern organization in the CNS. This regulatory factor has an essential role in spinal cord motor neuron and early posterior hindbrain development. In the anterior CNS, however, there is only a limited number of foci of RA synthesis, and less attention has been placed on regions such as the anterior hindbrain where RA synthesizing enzymes are absent. This study shows that a rich source of RA lies around the hindbrain from the RA synthetic enzyme retinaldehyde dehydrogenase-2 (RALDH2) present in the surrounding meninges and mesenchyme by embryonic day 13. RALDH2 is not distributed uniformly throughout the meninges but is restricted to territories over the developing hindbrain, suggesting that RA signaling may be localized to those regions. Further regulation of RA signaling is provided by the presence of a RA sink in the form of the CYP26B1 RA catabolic enzyme expressed in deeper regions of the brain. As a guide to the neural anatomy of hindbrain RA signaling, we used a mouse transgenic for a lac $Z$ reporter gene driven by a RA response element (RAREhsplacZ) to identify regions of RA signaling. This reporter mouse provides evidence that RA signaling in the hindbrain after embryonic day 13 occurs in the regions of the cerebellum and precerebellar system adjacent to sources of $\mathrm{RA}$, including the inferior olive and the pontine nuclei.
\end{abstract}

Key words: pontine nuclei; inferior olive; germinal trigone; cerebellum; precerebellar system; mouse

\section{Introduction}

Vitamin A (retinol) is required for normal embryonic development. Its metabolic product, retinoic acid (RA), mediates the majority of its actions by binding to specific nuclear receptors and regulating gene transcription. In the developing brain, RA influences the early stage of neural development and is necessary to set up patterned territories of cell groups. Essential for the control of RA in the embryo are the synthetic and catabolic enzymes that are spatially distributed to create zones of high and low RA (McCaffery et al., 1999; Swindell et al., 1999; Abu-Abed et al., 2003; Deng et al., 2003). The role of RA in CNS pattern development has been examined in greatest detail in the early hindbrain. The hindbrain itself does not express high amounts of RA-synthesizing enzymes; however, a source of RA for hindbrain patterning lies in the adjacent spinal cord and surrounding mesenchyme that express high levels of retinaldehyde dehydrogenase-2 (RALDH2) (Guthrie, 1996; Niederreither et al., 1997; Swindell et al., 1999). This posterior source of RA would correspond with a posterior function for RA in hindbrain development, which is consistent with the phenotype of the null mutants of RALDH2 (Niederreither et al., 2000) or RA receptors $\alpha$ and $\beta$ (Dupe et al., 1999), each of which exhibits disorganization

\footnotetext{
Received Feb. 26, 2003; revised June 3, 2003; accepted June 30, 2003.

This work was supported by National Institutes of Health Grant HD05515 and NASA Grant NAG2-1438 (P.M.) and the Japanese Ministry of Education, Science, Culture, and Sports Grant 10680739 and University of Tsukuba Special Research Projects grant (M.Y.). We thank Lynn Doucette for her excellent work on Figure 1.

Correspondence should be addressed to P. McCaffery, University of Massachusetts, E. Kennedy Shriver Center, 200 Trapelo Road, Waltham, MA 02452. E-mail: peter.mccaffery@umassmed.edu. Copyright $\odot 2003$ Society for Neuroscience $\quad$ 0270-6474/03/237610-11\$15.00/0
}

of the posterior rhombomeres. In contrast, the catabolic enzyme CYP26A1 is expressed in the early anterior hindbrain, where it inactivates RA that may diffuse to the anterior extent of the hindbrain (Abu-Abed et al., 2001; Sakai et al., 2001).

$\mathrm{RA}$ is thus likely to play an integral role in the development of the early posterior hindbrain. Little is known regarding the distribution and function of RA at later periods. A developmental requirement for $\mathrm{RA}$, however, is suggested by the teratogenic effects of RA at these later times. The studies of Lammer and Armstrong (1992) on RA-exposed human embryos indicate that certain regions of the hindbrain are acutely sensitive to RA teratogenicity, specifically the cerebellum as well as the pontine nuclei and inferior olive. A common denominator of these tissues is their derivation from a shared neuroepithelium. This relatively late-arising germinal zone of the brain is the rhombic lip (see Fig. 1 ), consisting of the germinal trigone and the anterior and posterior precerebellar neuroepithelium, and lies at the dorsal edge of the neural tube immediately posterior to the cerebellum (Altman and Bayer, 1997; Wingate, 2001). From these neuroepithelia arise the pontine neurons, inferior olive, lateral reticular, and external cuneate nuclei and external granule cells of the cerebellum.

If RA signaling is required for the development of components of the precerebellar system, then they must be situated in proximity to a source of RA. It is currently accepted that RA is not synthesized in the anterior hindbrain (Maden, 1999; Gavalas and Krumlauf, 2000; Niederreither et al., 2000). However, these studies do not consider an extraneural source. This study demonstrates that by embryonic day 13 (E13), the meninges contain active RALDH2 enzyme and release high amounts of RA for the 

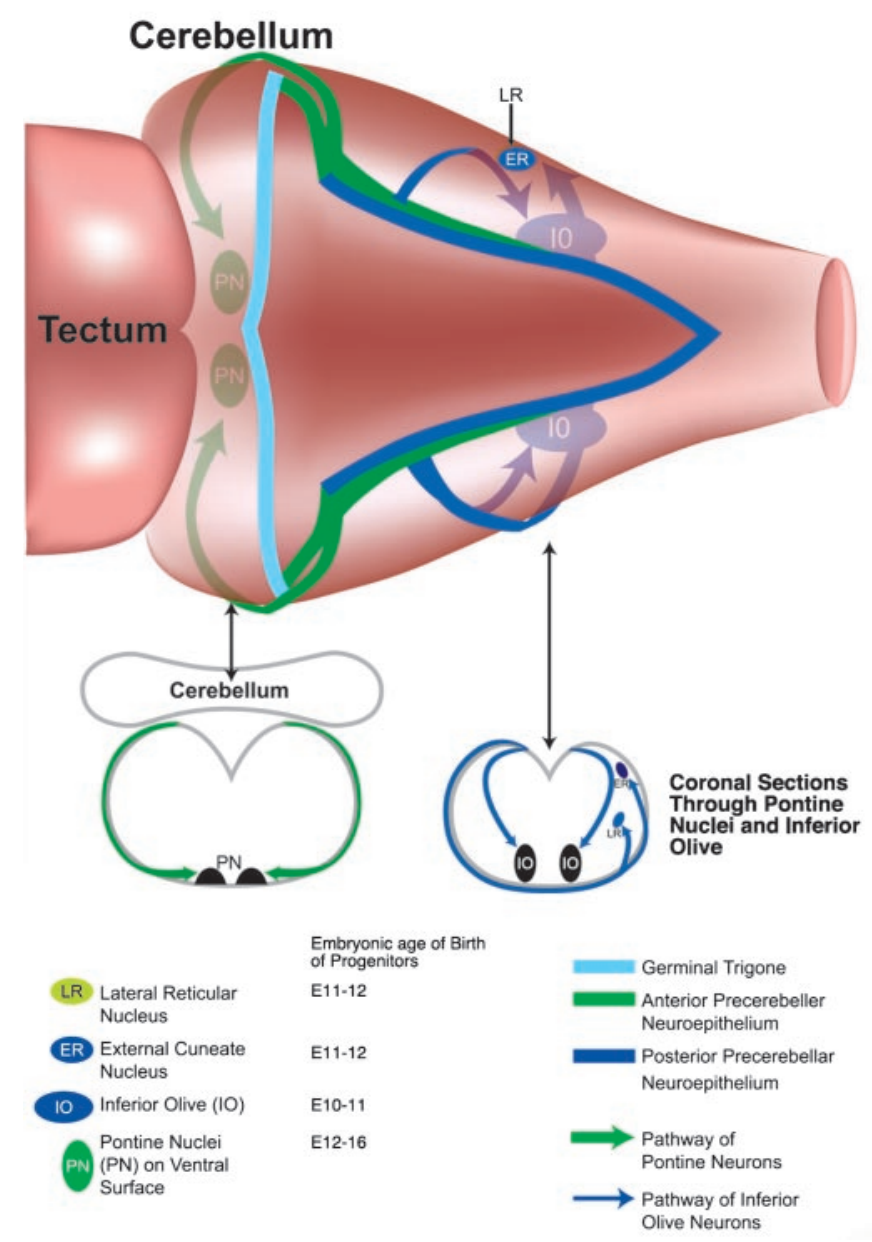

Figure 1. Pathways of migration of neurons born from the neuroepithelium of the rhombic lip.

outer layers of the developing brain. RALDH2 is restricted to specific territories of the meninges, and this likely contributes to the patterning of RA signaling in the components of the precerebellar system. The contrary metabolic route, the catabolism of $\mathrm{RA}$, is also used in the hindbrain to control the extent of RA patterning. As an initial indication of regions in which synthesized RA may act, we used a RAREhsplacZ RA reporter mouse (Rossant et al., 1991) to label areas of RA activation. The results imply that the pontine nuclei and inferior olive are two components of the precerebellar system in which RA signaling occurs.

\section{Materials and Methods}

Animals. The mice used in these studies were obtained from an in-house RAREhsplacZ colony originally obtained from Dr. Janet Rossant (Rossant et al., 1991). Embryos were staged following Theiler's criteria (Theiler, 1972), in which the day of conception is defined as embryonic day 0. The pregnant animals were killed by cervical dislocation under isofluorane anesthesia, and the embryos were removed from the uterus and decapitated. Embryonic brains were quickly dissected in ice-cold RPMI tissue culture medium with $10 \%$ fetal calf serum.

Preparation of embryos. For whole-mount in situ hybridization, tissues were immersed in $4 \%$ paraformaldehyde in $0.1 \mathrm{~m}$ phosphate buffer, $\mathrm{pH}$ 7.4 , and fixed at room temperature for $2 \mathrm{hr}$. For section in situ hybridization, the embryos were perfused with the same fixative, and the heads were postfixed overnight. In both cases, after fixation, the embryo heads were transferred to $30 \%$ sucrose in phosphate buffer until they sank and were stored at $-80^{\circ} \mathrm{C}$ until use. For development for $\beta$-galactosidase, the embryos were fixed for $30 \mathrm{~min}$ in $0.2 \%$ glutaraldehyde and $2 \mathrm{mM}$
$\mathrm{MgCl}_{2}$ in PBS and stained for $\beta$-galactosidase activity with $2 \mathrm{mg} / \mathrm{ml}$ 5-bromo-4-chloro-3-indolyl- $\beta$-D-galactopyranoside (X-gal) with $3.3 \mathrm{~mm}$ potassium ferricyanide, $3.3 \mathrm{~mm}$ potassium ferrocyanide, and $6 \mathrm{~mm} \mathrm{MgCl}$.

In situ hybridization. For whole-mount in situ hybridization, the tissues stored in sucrose at $-80^{\circ} \mathrm{C}$ were allowed to thaw and passed through a methanol gradient, 25, 50, 75, and $100 \%$ in PBS with $0.1 \%$ Tween $20 ; 5$ min each. The brains were stored in $100 \%$ methanol at $-20^{\circ} \mathrm{C}$ for up to several days. The samples were rehydrated in a methanol gradient (100, 75,50 , or $25 \%$, PBS plus $0.1 \%$ Tween 20 ; PBST) and treated with proteinase $\mathrm{K}(10 \mu \mathrm{g} / \mathrm{ml}$ in PBST $)$ for 10-11 min for E13 brain, 12-13 min for E15 brain, and 14-15 min for E17 brain at room temperature (RT). The enzyme was then inhibited with glycine $(2 \mathrm{mg} / \mathrm{ml}$ PBST) for $10 \mathrm{~min}$. The slides were then washed at RT with PBST twice for 5 min and fixed with $4 \%$ paraformaldehyde with $0.1 \%$ glutaraldehyde for $20 \mathrm{~min}$ at RT. After three 5 min PBST washes, the tissue was incubated in prehybridization solution (50\% formamide, $5 \times$ SSC, $\mathrm{pH} 4.5,50 \mu \mathrm{g} / \mathrm{ml}$ yeast tRNA, 50 $\mu \mathrm{g} / \mathrm{ml}$ heparin, and $1 \%$ SDS) for $1 \mathrm{hr}$ at RT. Prehybridization solution was replaced by hybridization mixture (1-2 ng probe/ml of prehybridization solution), and tissues were incubated at $70^{\circ} \mathrm{C}$ overnight. The tissue was washed in solution 1 ( $50 \%$ formamide, $1 \%$ SDS, and $5 \times$ SSC, $\mathrm{pH} 4.5)$, three times for $30 \mathrm{~min}$ each at $70^{\circ} \mathrm{C}$, then in solution $3(50 \%$ formamide, $2 \times \mathrm{SSC}$, $\mathrm{pH} 4.5$ ) three times for $30 \mathrm{~min}$ each at $65^{\circ} \mathrm{C}$, followed by two $5 \mathrm{~min}$ washes of PBST at RT. For antibody reaction, tissues were preblocked with $10 \%$ normal goat serum in PBST for $2.5 \mathrm{hr}$ at RT. Anti-digoxigenin (DIG) antibody alkaline phosphatase conjugated (Boehringer Mannheim, Mannheim, Germany) was preabsorbed with liver acetone powder and diluted 1:1000 in PBST; this was incubated with the tissue overnight at $4^{\circ} \mathrm{C}$. Tissues were washed in Tris-buffered saline with $0.1 \%$ Tween 20 (TBST), including $1 \mathrm{~mm}$ levamisole, five times for $30 \mathrm{~min}$ each, left $1-1.5 \mathrm{hr}$ five times at RT, then overnight at $4^{\circ} \mathrm{C}$. After washing in $100 \mathrm{~mm} \mathrm{NaCl}, 100 \mathrm{~mm}$ Tris, $\mathrm{pH} 9.5,50 \mathrm{~mm} \mathrm{MgCl}_{2}$, and $0.1 \%$ Tween 20 (NTMT), the color reaction for alkaline phosphatase was performed using nitroblue tetrazolium and 5-Bromo-4-chloro-3-indolyl phosphate (Sigma, St. Louis, MO) with $1 \mathrm{~mm}$ levamisol in the dark.

For section in situ hybridization (Dellovade et al., 2000), the tissues stored in sucrose at $-80^{\circ} \mathrm{C}$ were allowed to thaw, and $100 \mu \mathrm{m}$ sections in $5 \%$ agarose were cut on a vibratome into RNase-free PBS in $200 \mu \mathrm{m}$ netwells (Corning, Corning, NY) and treated with $6 \%$ hydrogen peroxide in PBST for $1 \mathrm{hr}$ at room temperature. The sections were then treated with $10 \mu \mathrm{g} / \mathrm{ml}$ proteinase $\mathrm{K}$ in PBST for $15 \mathrm{~min}$ at room temperature and stopped with $2 \mathrm{mg} / \mathrm{ml}$ glycine in PBST for $10 \mathrm{~min}$. After washing twice in PBST, the sections were postfixed in $4 \%$ paraformaldehyde and $0.2 \%$ glutaraldehyde in PBST for $20 \mathrm{~min}$, washed twice again, and placed in glass scintillation vials with $2 \mathrm{ml}$ of prehybridization solution for incubation at $56^{\circ} \mathrm{C}$ for $1 \mathrm{hr}$. The probe was diluted in prehybridization solution at $0.5 \mu \mathrm{g} / \mathrm{ml}$, added to the sections, and incubated at $56^{\circ} \mathrm{C}$ with gentle shaking overnight. The sections were transferred to small disposable containers of $20 \mathrm{ml}$ volume and washed three times for $30 \mathrm{~min}$ in solution 1 at $56^{\circ} \mathrm{C}$ and washed in similar manner with solution $2(50 \%$ formamide, $2 \times \mathrm{SSC}$, $\mathrm{pH} 4.5)$. The sections were then washed three times for $5 \mathrm{~min}$ with TBST at room temperature, blocked for $1 \mathrm{hr}$ in TBST with $10 \%$ sheep serum, and then incubated overnight at $4^{\circ} \mathrm{C}$ with gentle shaking in anti-DIG alkaline phosphatase-conjugated antibody at 1:2000 dilution. In a volume of $2 \mathrm{ml}$, the sections were washed for $5 \mathrm{~min}$, three times with TBST, and then washed for $1 \mathrm{hr}$, five times while gently shaking before sitting overnight without shaking in TBST at $4^{\circ} \mathrm{C}$. The sections were washed in NTMT for $15 \mathrm{~min}$, three times with shaking, and the color reaction for alkaline phosphatase was performed using nitroblue tetrazolium and 5-bromo-4-chloro-3-indolyl phosphate (Sigma) with 1 $\mathrm{mm}$ Levamisol in the dark before mounting on slides.

The CYP26B1 probe was kindly donated by Dr. Hamada (Osaka University, Japan). CRABPI probes were derived by PCR amplification of cDNA from E13 heads using the specific primers CAA CGA TGA GCT AAT CCT GAC A AND GCA GCC AAC CAG TTT AAT GA derived from the available CRABPI sequence (Vaessen et al., 1989). The resulting fragment, spanning nucleotides 441-743 were subcloned into pCRII-TOPO (Invitrogen, Gaithersburg, MD).

Hindbrain explant culture. E12 or E14 hindbrains were dissected in ice-cold sterile RPMI medium, the meninges were removed, and the 
hindbrain was placed dorsal side down on a 8 $\mu \mathrm{m}$ pore size transwell, $24 \mathrm{~mm}$ in diameter (Corning) using a technique similar to that described by de Diego et al. (2002). Serum-free medium under the netwell, just sufficient to cover the explant, consisted of Neurobasal medium (Invitrogen) together with N2 supplement (Invitrogen), GlutaMAX-1 (Invitrogen), and antibiotic-antimycotic mix (Invitrogen). The explant was incubated for $2 \mathrm{~d}$ at $36^{\circ} \mathrm{C}$ in $5 \% \mathrm{CO}_{2}$ with high humidity.

Immunocytochemistry. Immunocytochemistry was performed on cryostat-sectioned tissue. Rabbit antibodies to $\beta$-galactosidase were from Cortex Biochem Inc. (San Leandro, CA), and rabbit anti-RALDH2 antibodies were made against recombinant protein (Berggren et al., 1999). Double labeling for these two antibodies was performed sequentially first for RALDH2 with a biotinylated anti-rabbit antibody (Jackson ImmunoResearch, West Grove, PA) and Cy2-conjugated streptavidin (Jackson ImmunoResearch), allowing saturation of the primary antibody. This was followed by rabbit anti- $\beta$-galactosidase and a Cy3-conjugated antirabbit antibody (Jackson ImmunoResearch).

Measurement of RA concentration. Measurement of RA release was performed by the incubation of tissue in $300 \mu \mathrm{l}$ of $\mathrm{L} 15\left(\mathrm{CO}_{2}\right.$ modification) medium overnight at $37^{\circ} \mathrm{C}$ in a $5 \% \mathrm{CO}_{2}$ atmosphere. The tissue was spun down, the supernatant was removed, and $100 \mu \mathrm{l}$ was assayed for RA on the Sil-15 RA reporter cell line, developed by Dr. M. Wagner (Wagner et al., 1992), grown on a 96 well plate. $\beta$-galactosidase synthesized in response to RA was measured by reaction with $\mathrm{X}$-gal and quantified on an ELISA plate reader at $630 \mathrm{~nm}$. RA concentrations were determined by comparison with an RA standard curve, and protein concentration was measured using the BCA assay (Pierce, Rockford, IL).

\section{Results}

\section{Development of the precerebellar} system from the rhombic lip

The anterior-most region of the germinal zone of the rhombic lip is the germinal trigone, which gives rise to the progenitors of the cerebellar granule cells of the external granule layer. The rhombic lip over the medulla and pons, which is subdivided into the anterior and posterior precerebellar neuroepithelium, generates neurons of the "precerebellar system" (Altman and Bayer, 1987, 1997). The components of the precerebellar system all project to the cerebellum and consist of the pontine and reticulotegmental nuclei in the pons, generated from the anterior precerebellar neuroepithelium and the inferior olive, external cuneate, and lateral reticular nuclei, which arise from the posterior precerebellar neuroepithelium (Altman and Bayer, 1987). In the chick, at least, the posterior precerebellar system also contributes to the neurons of the pontine nuclei (Marin and Puelles, 1995). Figure 1 shows the migratory route of the neuronal progenitors of the pontine nuclei and inferior olive, both of which are characteristically sensitive to RA teratogenicity (Lammer and Armstrong, 1992). The neurons of the pontine nuclei (PN) are born from the anterior precerebellar neuroepithelium of the rhombic lip and migrate around the surface of the medulla, under the meninges, to reach the medioventral surface
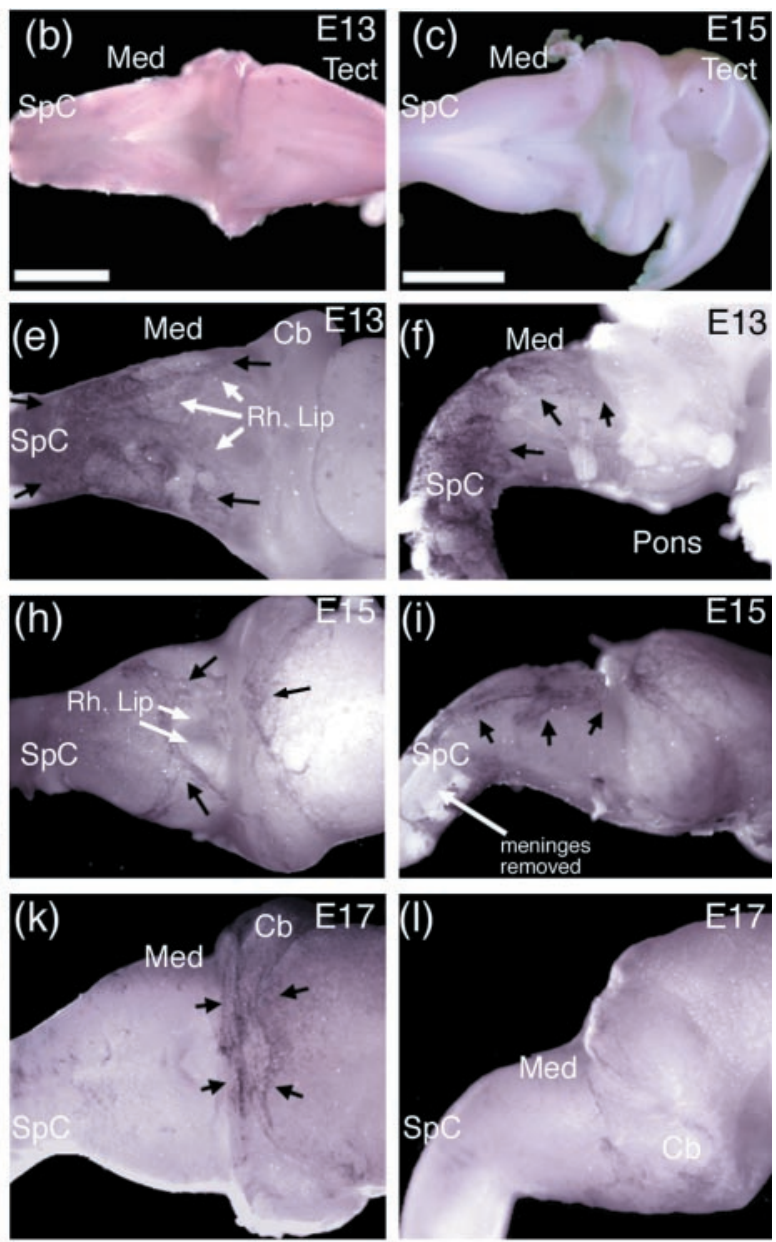

Figure 2. In situ hybridization for RALDH2 in the developing hindbrain at E11.5 $(a), \mathrm{E} 13(b, d-f), \mathrm{E} 15(c, g-i)$, and E17 $(j-l)$ in dorsal $(a-c, e, h, k)$, ventral $(d, g, j)$, and lateral $(f, i, l)$ views. At E11.5, RALDH2 is expressed in the mesenchyme (mesen.) surrounding the somites of the trunk $(a)$ but is absent from the mesenchymal tissues over the dorsal brain. If the mesenchymal 列 and surrounds the dorsal rhombic lip. RALDH2 levels have fallen by E15 but are still higher in the meningeal network around the region of the rhombic lip ( $h$, black arrows). Overall levels in the meninges are above those in the underlying CNS, indicated by the staining intensity in the spinal cord ( $i$ ) where the meninges have peeled off (white arrow). AtE 17, RALDH2 levels have risen in the region of the developing pontine nuclei ( $j$, black arrows), and although RALDH2 is low in the dorsal medulla and rhombic lip, it is higher over the cerebellum and tectum ( $k$, black arrow). Med, Medulla; $\mathrm{Cb}$, cerebellum. Black arrows point to the outer edge of meningeal RALDH2 spread. Scale bars, $1 \mathrm{~mm}$.

of the pons. There may also be some contribution of cells from the posterior precerebellar neuroepithelium. In contrast, the olivary neurons are born only from the posterior precerebellar neuroepithelium and migrate internally within the medulla to form the inferior olive (IO). This same neuroepithelium also gives rise to neurons of the external cuneate and lateral reticular nuclei. Like the cells of the pontine nuclei, these neurons migrate under the meninges, but they cross the ventral midline and then migrate up to their final target site. The nuclei of the precerebellar system act as relays for input into the cerebellum.

\section{RA synthesis in the developing hindbrain}

The patterning of RA signaling in the early brain is influenced by the distribution of the RA synthesizing and catabolizing enzymes. A likely supply of RA for the posterior hindbrain during this early developmental period (E7.5-9.0) is the spinal cord and its surrounding mesenchymal tissue, which express high amounts of the RALDH-2 enzyme (Guthrie, 1996; Niederreither et al., 1997; 
Maden, 1999; Swindell et al., 1999; Niederreither et al., 2000). A requirement for RA signaling in the later hindbrain, however, has been less considered because of the presumed absence of an RA source. We have previously shown that only low levels of RAsynthesizing enzymes are present in the neural hindbrain (Dräger and McCaffery, 1994). By whole-mount in situ hybridization, $R A L D H 2$ is present in the mesenchyme surrounding the somites of the trunk at E11.5 but is absent from the hindbrain or midbrain (Fig. $2 a$ ). Neither is RALDH2 present around the hindbrain or midbrain at the later developmental stages of E13 and E15 when the standard whole-mount technique is followed where the meninges is removed (Fig. $2 b, c$ ). If the meninges are allowed to remain in place, however, this enzyme is shown to be present in localized regions of the surrounding meninges. Figure $2 d-l$ shows RALDH2 hindbrain in situ hybridization at E13, E15, and E17 with the meninges attached. RALDH2 is present at high levels in the meninges around the spinal cord (Fig. $2 d, e$ ), whereas there are only relatively low amounts in the ventral meninges of the hindbrain (Fig. 2d). However, at E13 strong RALDH2 expression continues from the spinal cord to cover the lateral and dorsal medulla up to the edge of the neural tube that constitutes the rhombic lip (Fig. 2e,f, black arrows) (see also Fig. 1). By E15, strong RALDH2 expression is restricted to a meningeal network, which lies over the rhombic lip (which is now significantly smaller) (Fig. $2 h$, black arrows). RALDH2 is also expressed over the midline region of the cerebellum in a continuation of this meningeal network (Fig. 2h, black arrow). Although RALDH2 levels are lower in meninges surrounding other brain regions, the levels are higher than the surface of the brain itself, indicated by the very low staining in the spinal cord where the meninges had detached (Fig. $2 i$, white arrow). By E17 levels of RALDH2 are very low over the rhombic lip, the birth place of the precerebellar nuclei (Fig. $2 k$ ) but, interestingly, $R A L D H 2$ is now detectable in one precerebellar nuclei site to which the rhombic lip progenitors have migrated, i.e., the developing pontine nuclei (Fig. $2 j$, black arrows). $R A L D H 2$ expression is also stronger over the cerebellum and caudal tectum (Fig. $2 k$, black arrows).

It is possible that RA synthesized by RALDH 2 in the meninges may serve an autocrine function and is not released from the cells. To determine whether RA was released from the meninges and how this compares to amounts released by the neural brain, approximately equal amounts of tissues were dissected from a variety of regions of the spinal cord and hindbrain. These tissues were incubated overnight in L15 tissue culture medium, the tissue was pelleted, and the medium was assayed for content of RA using an RA reporter cell line (sil-15) (McCaffery et al., 1992; McCaffery and Dräger, 1994a). Values were compared with an RA standard curve and plotted as a ratio of the total protein in the pellet (Fig. 3). The spinal cord, which expresses RALDH2 in the motoneurons and is known to be a potent source of RA (McCaffery and Dräger, 1994a; Sockanathan and Jessell, 1998), released RA, whereas the hindbrain was entirely negative. The low release of RA by the hindbrain contrasted with the surrounding meninges, which released much greater amounts of RA into the medium, the highest levels being in the meninges around the cerebellum.

\section{RA binding proteins in the hindbrain}

It has been shown previously that the RAR $\alpha$ RA receptor is present in the medulla (Ruberte et al., 1993) and the RXR $\alpha$ and $\beta$ receptors are present throughout the embryonic brain (Dollé et al., 1994), but the expression of these receptors is not restricted to a particular locale and does not point to one particular region in the anterior hindbrain where RA signaling may take place. How-

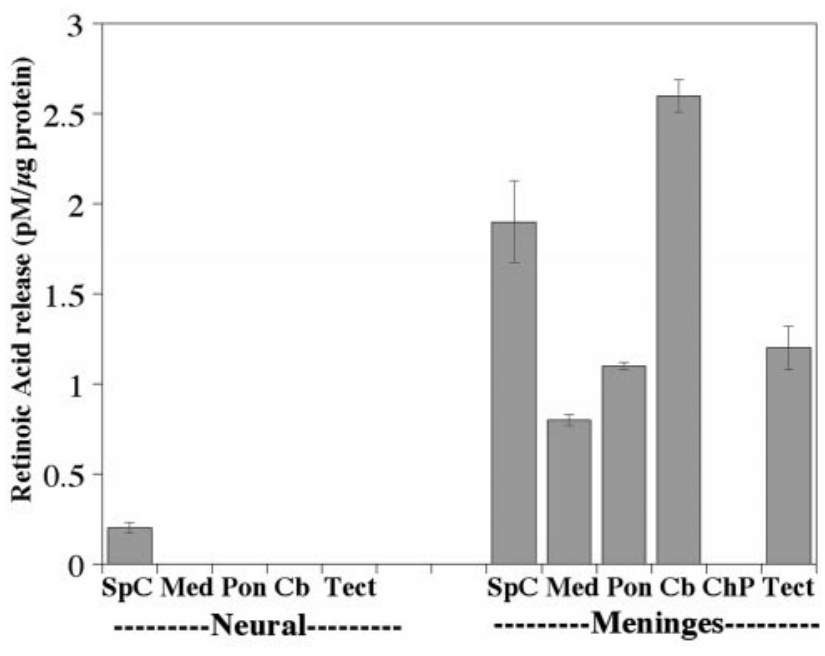

Figure 3. Relative amounts of RA released by the meninges and CNS atE16. Similar amounts of tissues were dissected from the spinal cord (SpC), pons (Pon), tectum (Tect), medulla (Med), and cerebellum $(\mathrm{Cb})$. The meninges around these tissues was also dissected as well as the choroid plexus (ChPI) of the fourth ventricle. The tissues were incubated overnight in tissue culture medium, and the medium was assayed for content of RA using an RA reporter cell line. Absolute values were determined by comparison to an RA standard curve and plotted as a ratio of the total protein in the tissue. RA release from the spinal cord was detectable, whereas the hindbrain was entirely negative. The meninges released significant amounts of RA into the medium, the highest levels from the meninges around the cerebellum.

ever, several other components of the RA signaling pathway are localized to territories of the medulla and pons. We have shown that the synthetic enzyme RALDH2 is expressed in the meninges surrounding the hindbrain. The cellular RA binding protein-I (CRABPI) is also expressed in several locations on the surface of the brain. Dolle et al. (1990) initially described CRABPI in the pontine nuclei of the hindbrain by in situ hybridization of sections. Figure 4 shows the distribution of CRABPI by wholemount in situ hybridization. At E12 by in situ hybridization with the meninges removed before fixation, CRABPI is expressed strongly along the lateral edge of the dorsal hindbrain as well as along two sets of more ventral longitudinal stripes (Fig. 4a,b). The anterior limits of these lie at the rhombomeres $3 / 4$ boundary (Maden et al., 1992), but expression continues along the posterior edge of the cerebellum (Fig. 4a). The removal of the meninges can detach the neurons that migrate under this layer. If the embryo is first fixed and the meninges then removed from the brain, many of the migrating surface neurons remain attached. CRABPI is evident both in the rhombic lip as well as the cells of the anterior precerebellar stream (aPS) (Fig. 4c) at E13. The anterior precerebellar stream has reached over the ventral pons but has yet to reach the pontine nuclei (Fig. $4 d$ ). A second migratory pathway is also evident over the ventral posterior medulla, which is likely to be the posterior precerebellar stream (Fig. $4 d$ ). The posterior stream consists of neurons that populate the external cuneate and lateral reticular nuclei (Fig. 1). Leaving the meninges on the hindbrain at E17.5 in Figure 4, $e$ and $f$, the anterior precerebellar stream is seen to reach the pontine nuclei. It is thus apparent that $C R A B P I$ is present in all the precerebellar neurons that migrate under the meninges. These results suggest that RA regulated transcription occurs in the developing pontine nuclei as the pontine neuronal progenitors express CRABPI as they migrate from the rhombic lip under the RALDH2 rich meninges (Fig. 4). The RA receptors are not restricted to a particular region (Ruberte et al., 1993; Dollé et al., 1994), whereas other regulatory 
components for RA metabolism (CRABPI and RALDH2) are localized. This led us to examine RA signaling through the use of a RAREhsplacZ reporter transgenic mouse (Rossant et al., 1991) to determine the spatial relationship between enzyme localization and LacZ expression.

\section{RAREhspLacZ expression in the hindbrain}

RAREhsplacZ reporter transgenic mice are transgenic for a RAREhsplacZ construct on a background of an outbred CD 1 strain. Three copies of the RA response element (RARE) from $R A R \quad \beta$ are upstream of the promoter from the mouse heat-inducible hsp68 gene driving the lac $Z$ reporter gene. The result of this transgene is that mice respond to endogenous RA by synthesizing $\beta$-galactosidase and they can be used to identify regions of retinoic acid signal transduction. Earlier studies have shown that the reporter gene responds to RA and not to activators of other nuclear receptors such as thyroid hormone and vitamin D (Rossant et al., 1991). This RAREhsplacZ transgenic mouse precisely reports on regions of RA signaling in several regions of the embryo. For instance, RAREhsplacZ is strongly induced in the dorsal and ventral halves of the retina where RA is synthesized by, respectively, the enzymes RALDH1 and RALDH3 (Wagner et al., 2000) but is absent in the central stripe of low RA where the RA catabolic enzyme CYP26A1 is present (McCaffery et al., 1999). The $R A R E h s p l a c Z$ construct is also induced in regions of RA signaling in the tectum (Wagner et al., 2000) and neuromeres of the cortex (Smith et al., 2001). This transgenic mouse strain has also been used to investigate RA signaling in the developing mouse heart (Moss et al., 1998) and to show changes in RA signaling in the CYP26A1 null mutant (Sakai et al., 2001).

Figure 5 shows the expression of RAREhsplac $Z$ in a sagittal section through a whole mount labeled postnatal day 3 hindbrain. The spinal cord is intensely labeled, as would be expected given the high levels of RALDH2 and thus RA in this region (McCaffery and Dräger, 1994a; Sockanathan and Jessell, 1998). In the hindbrain, however, three sites are highlighted: the Purkinje cells of the posterior cerebellum, the pontine nuclei, and the inferior olive (Fig. 5). This suggests that RA signaling is of particular importance in the subsystem of the hindbrain, which consists of the cerebellum and the precerebellar nuclei that innervate it.

\section{RAREhsplacZ expression and its relationship to the RA synthetic (RALDH2) and catabolic (CYP26B1) enzymes and CRABPI}

The most striking feature of RAREhsplacZ expression in sections through the hindbrain is its prominent expression over the surface of the brain at E13, E15, and E17 (Figs. 6-8). These are the
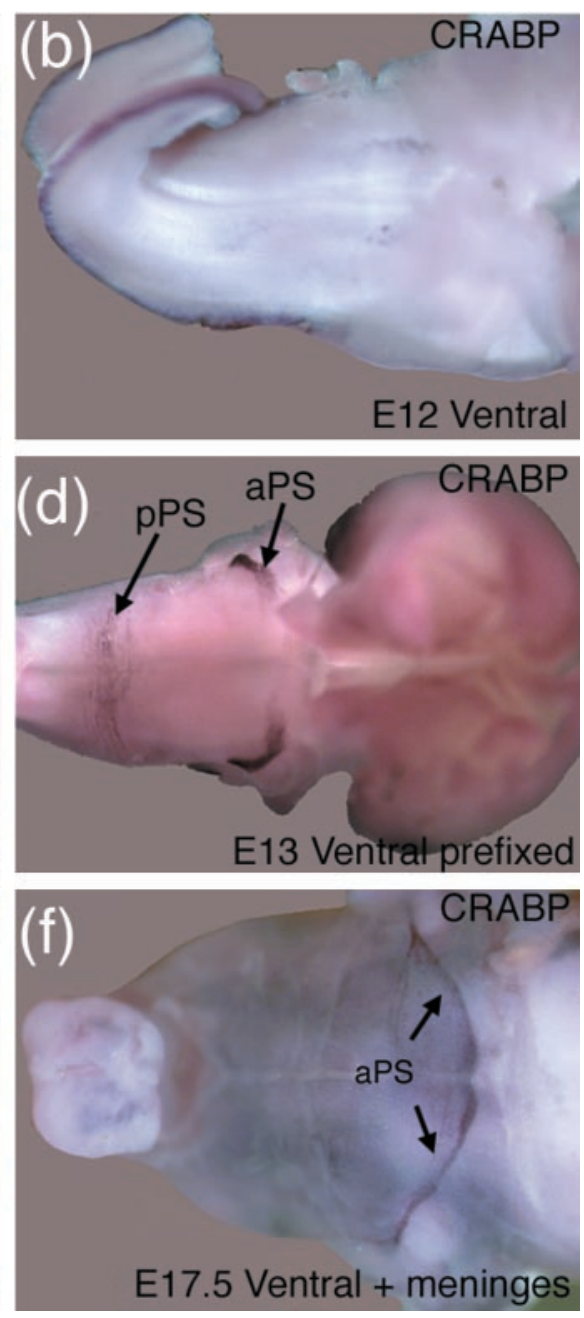

Figure 4. Whole-mount in situ hybridization of $\mathrm{CRABP} /$ in hindbrain at $\mathrm{E} 12(a, b)$ and $\mathrm{E} 13(c, d)$ without meninges and at $\mathrm{E} 17.5$ with meninges $(e, f)$. At E12 with the meninges removed before fixation $(a) C R A B P /$ is initially expressed along the dorsal edge of the hindbrain and the posterior edge of the cerebellum. If the brain is first fixed, then fewer of the neurons migrating under the 列 reaching at this age) the pontine nuclei. A minor stream of cells around the posterior medulla $(d)$, the posterior precerebellar stream (pPS, arrow), is likely a second stream of cells derived from the posterior precerebellar neuroepithelium that migrate under the meninges to populate the external cuneate and lateral reticular nuclei. If the meninges are left on at E17.5, the anterio precerebellar stream (aPS) is clearly evident and has reached the pontine nuclei $(e, f)$. Scale bars, $1 \mathrm{~mm}$.

neural progenitors born in the dorsal precerebellar neuroepithelium that migrate ventrally to form the nuclei of the precerebellar system (Fig. 1). A certain population of these progenitors migrates over the surface of the brain. Of these, those born from the anterior precerebellar neuroepithelium form the pontine nuclei, whereas those born from the posterior precerebellar neuroepithelium form the lateral reticular and external cuneate nuclei. These cells are RAREhspLacZ-positive as they leave the precerebellar neuroepithelium, seen most clearly in Figure $7 a-d$, and those from the anterior precerebellar neuroepithelium remain positive as they mature in the pontine nuclei (see Fig. $10 a-e$ ). It is evident from these sections, as well as from Figure 11, that both groups of cells migrating under the RA-rich meninges are responding to RA, as indicated by their RAREhspLacZ expression. Two other hindbrain regions situated at the peripheries of the hindbrain express RAREhsplacZ: the basal plate and the inferior olive. The ventral basal plate intensely expresses the transgene at all tested ages, and RAREhsplacZ-positive cells stream 


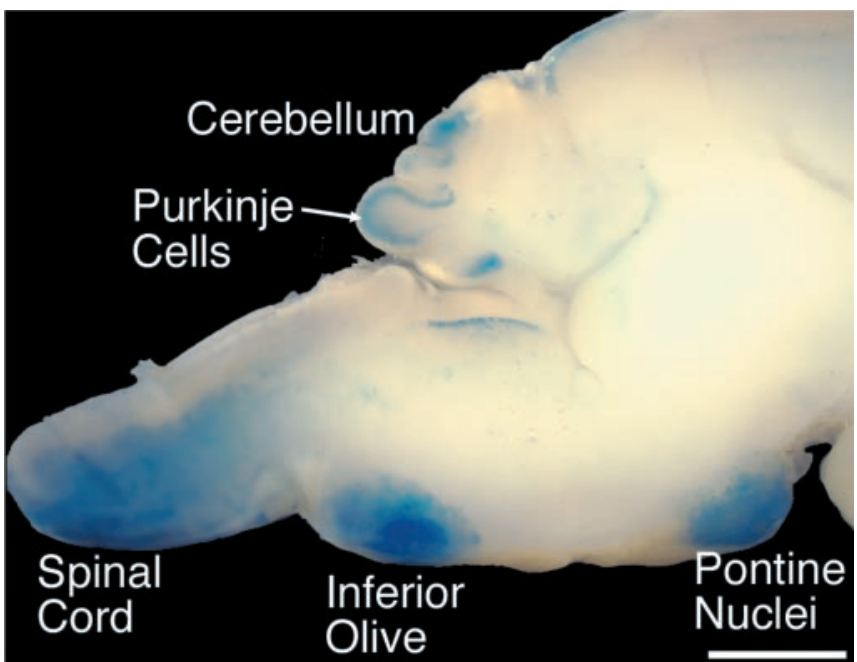

Figure 5. RAREhsplacZ expression in a sagittal section of postnatal day 3 hindbrain. A glutaraldehyde-fixed postnatal day 3 hindbrain was sliced immediately lateral to the midline and stained for $\beta$-galactosidase activity. In the hindbrain, the inferior olive and pontine nuclei are particularly strongly labeled as well as the Purkinje cells (PC) in the cerebellum. Scale bar, 1 $\mathrm{mm}$. (a)

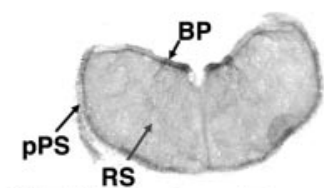

RAREhspLacZ

(d)

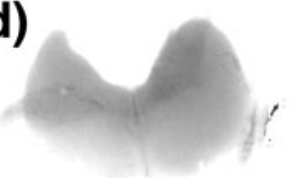

RALDH2

(g)

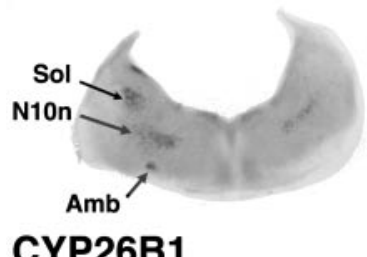

CYP26B1 (b)

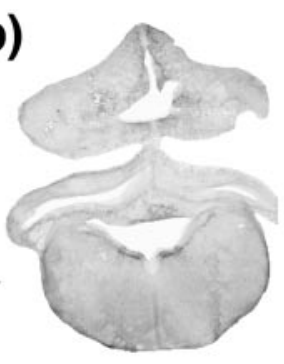

(e)

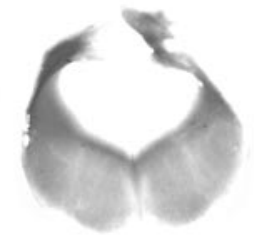

(f)
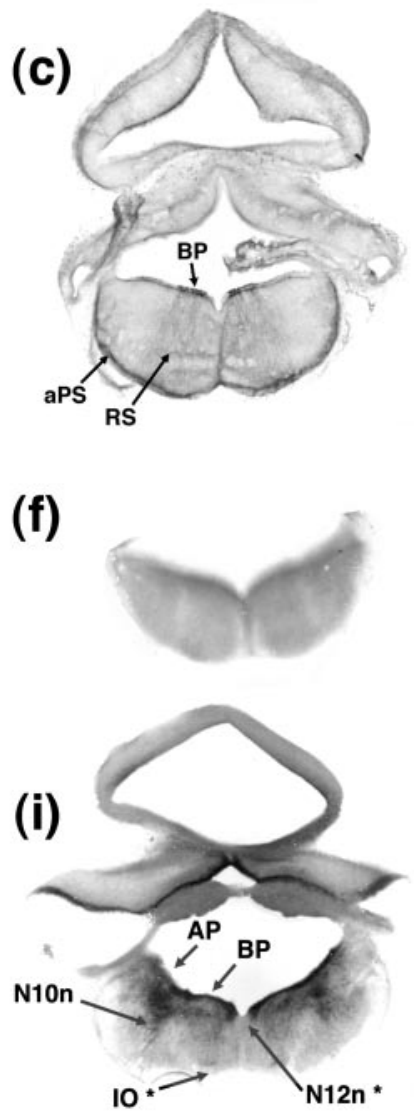

down toward the ventral surface of the hindbrain (Figs. $6 a, 7 a, 8 a$, RS) but the identity of these cells is unknown. RAREhspLacZ expression is evident in the inferior olive by E15, increasing in intensity at E17, but the strongest signals remain in the periphery of the inferior olive in its ventralmost extent (Fig. 8a,b).

It is presumed that RAREhsplacZ expression is highest around the periphery of the brain because it lies directly beneath the RALDH2-rich meninges. There are two restricted locations, however, where RALDH2 is also expressed: the external cuneate nucleus, which is a component of the precerebellar system, and the vestibular nucleus $(8 \mathrm{n})$, which, like the precerebellar nuclei, provides afferent input to the cerebellum (Fig. 7g). RA synthesis could not be detected from the E16 hindbrain (Fig. 3), but this could be because the regions of RALDH2 expression are too small to synthesize detectable amounts of RA. However, neither was the $R A R E h s p L a c Z$ reporter gene expressed within these nuclei (Fig. $8 c$ ), suggesting that the RALDH2 enzyme in these regions is not synthesizing RA, which is able to induce this transgene, e.g., the 9-cis-RA isomer may be synthesized in these nuclei.

Much of the expression of RAREhspLacZ in the periphery is attributable to the neural progenitors that are born in the dorsal precerebellar neuroepithelium and migrate ventrally around the hindbrain. The RAREhspLacZ-positive neurons from the anterior precerebellar neuroepithelium (Fig. 9a) are shown to be migrating directly under the RALDH2positive meninges (Fig. 9b). As the cells migrate under the meninges, their exposure to RA continues up to the point of reaching the pontine nuclei. The nuclei are weakly labeled with RALDH-2 antibodies, although they do not show labeling for RALDH2 by in situ hybridization (data not shown), and so this is likely to be nonspecific. The pontine nuclei are, however, situated close to a meningeal source of RA (Fig. 9d). RALDH2 expression in the ventral meninges is significantly lower than that in the dorsal meninges (Fig. 2) but this may be sufficient to maintain RAREhsplacZ expression. Although RALDH2 is strongly expressed in the anterior pituitary (Fig. 9d), as we have previously described (McCaffery and Drager, 1995), when this tissue is cultured and RA measured in the surrounding medium, in a similar manner to our experiments with meninges (Fig. 2), we are unable to detect RA release from this tissue. Given that RAREhspLacZ induction overlaps with RALDH2 in the pituitary (Fig. 9c), this may imply that RA is synthesized to regulate pituitary function but is contained within the cells. A second potential source of RA for the pontine neurons is RALDH1 in the nigrostriatal neurons of the midbrain (McCaffery and Dräger, 1994b) (Fig. $10 g-l$ ). However, these neurons are a significant distance from the pontine nuclei (Fig. 10a-e). Furthermore, this enzyme has significantly weaker activity, as compared with RALDH2 or 3 (McCaffery et al., 1992), and RAREh-
Figure 6. Comparison of RAREhsplacZ, RALDH2, and CYP26B1 in the E13 hindbrain without meninges. RAREhsplacZ ( $a-c$ ) expression is almost all distributed around the peripheries of the hindbrain in migrating cells of the posterior (pPS) and anterior (aPS) precerebellar stream and in the basal plate (BP), and the only labeled region within the brain is a stream of cell arising from the basal plate labeled the radial stream (RS). RALDH2 (d-f) is entirely absent from the brain, whereas CYP26B1 ( $g-i)$ is strongly expressed in the ventricular layer of the alar plate (AP) and basal plate (BP) and is also present in the region of the nucleus of the solitary tract (Sol), the dorsal nucleus of the vagus (N10n), and ambiguus nucleus (Amb). Several nuclei (labeled with asterisks) do not express CYB26B1, but the enzyme lies immediately adjacent to the cell group, and this includes the inferior olive ( $10^{*}$ ) and nuclei of the hypoglossal nerve (N12n*). Scale bar, $1 \mathrm{~mm}$. 
spLacZ (Fig. 10f) is induced only in the regions of highest RALDH1 expression (Fig. 10l). The only other embryonic RAsynthesizing enzyme, RALDH3, was not detected in the hindbrain by in situ hybridization.

The posterior precerebellar neuroepithelium is also a source of neural precursors that migrate around the brain, and both the anterior and posterior precerebellar streams are evident along the lateral E12 hindbrain labeled with CRABPI (Fig. 11a, broken line). Both streams of cells are responsive to RA, as suggested by their RAREhspLacZ expression at E13 (Fig. 11b). At this age, the anterior precerebellar stream derives from both the anterior and posterior precerebellar neuroepithelium, as is the case in the chick (Marin and Puelles, 1995). By E16 the majority of the cells of the anterior precerebellar stream come from the anterior precerebellar neuroepithelium, whereas the posterior precerebellar stream is reduced (Fig. 11c). By E18 the posterior precerebellar stream is no longer evident (Fig. 11d).

In contrast to the RA synthetic enzyme $R A L D H 2$, which is predominantly expressed around the brain in the meninges, the RA catabolic enzyme CYP26B1 is strongly expressed in the anterior ventricular surface as well as several hindbrain nuclei including the ambiguous nucleus, the dorsal motor nucleus of vagus (N10n), as well as the nucleus of the solitary tract (Figs. 6-8). The labeling at the anterior ventricular surface at E13 is highest in the alar plate (Fig. $6 h$ ) and is lower in the basal plate. By E15 CYP26B1 is absent from the basal plate in a complimentary pattern to the expression of RAREhspLacZ (Fig. 7d,l). Ventricular CYP26B1 expression is at its highest at E13 (Fig. 6h,i) in both the medulla and cerebellum. This labeling appears continuous with deeper levels of the medulla, overlapping with the regions where the dorsal nuclei are forming, suggesting that CYP26B1 progenitors born in the ventricular layer continue to express $C Y P 26 B 1$ as they migrate in. For certain hindbrain nuclei, such as the inferior olive at E13 (Fig. $6 h, i)$, the hypoglossal nucleus (N12n) at E13 and E15 (Figs. 6i, 7k), and the nucleus of the facial nerve (N7n) at E17 (Fig. 8k,l), CYP26B1 is not present in the nuclei itself but lies immediately adjacent and may play a "protective" role preventing RA exposure. The other catabolic enzyme identified in the developing embryo, CYP26A1 (White et al., 1996; Fujii et al., 1997) was not detectable by in situ hybridization in sections of E13, E15, or E17 hindbrains.

\section{RA induction of RAREhsplacZ in migrating neurons in hindbrain explants with the meninges removed}

To show that RA from the meninges is necessary for induction of RAREhspLacZ in the neurons migrating over the hindbrain, explants of E12 or E14 hindbrain were cultured without meninges, with or without the addition of RA (Fig. 12). RAREhsplacZ-positive neurons are not evident over the ventral surface of the E12 hindbrain at day 0 or after culture for $2 \mathrm{~d}$ (Fig. $12 a, b)$. However, if $10 \mathrm{~nm}$ RA is included in the serum-free medium, then the earliest neurons that migrate from the posterior (b)

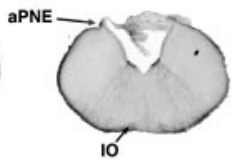

(f)

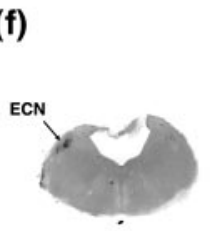

(j)

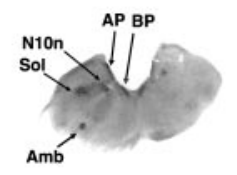

(c)
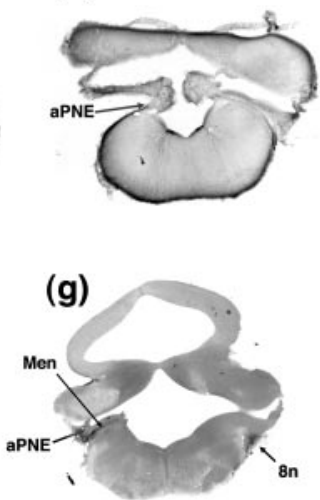

(k)

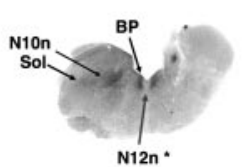

(d)

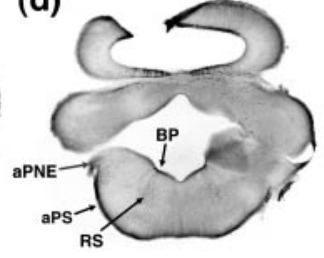

(h)
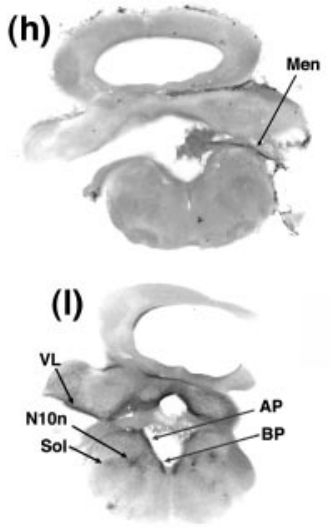

Figure 7. Comparison of RAREhsplacZ, RALDH2, and CYP26B1 in the E15 hindbrain without meninges. As found at E13, RAREh列 $(\mathrm{VL})$ and is also in the nucleus of the solitary tract (Sol), the dorsal motor nucleus of the vagus (N10n), and nucleus ambiguus (Amb) while the enzyme is expressed adjacent to the nuclei of the hypoglossal nerve (N12n ${ }^{*}$ ). Scale bar, $1 \mathrm{~mm}$.

precerebellar neuroepithelium are seen spreading from the lateral edge of the explant toward the midline (Fig. 12c). If the explant is started at E14, these same migrating neurons are already present over the caudal hindbrain (Fig. 12d). However, RAREhsplacZ is no longer present in migrating cells when the explants are cultured without the meninges (Fig. 12e), but after $2 \mathrm{~d}$ culture in $10 \mathrm{~nm}$ RA RAREhsplacZ is expressed in cells migrating over the rostral medulla that presumably derive from the anterior precerebellar neuroepithelium. These results imply that $R A$ required to induce $R A R E h s p l a c Z$ in these migrating neurons is derived from the meninges and that this can be replaced by adding back as little as $10 \mathrm{~nm}$ RA. RAREhsplacZ in the rostral stream (RS) seen, for instance, in Figure $6 a-c$, is weak at its ventral extent in Figure 12a. At this age it is inducible by RA (Fig. 12c). By E14 though (Fig. 12d), strong RAREhsplacZ expression in the rostral stream can no longer be further enhanced by the addition of 10 nM RA (Fig. 12f).

\section{Discussion}

The meninges as a source of growth factors for the brain

RA is known to profoundly affect gene expression in neurons and neuronal progenitors and, as a result, the CNS is particularly sensitive to null mutations of individual RA receptors, or combinations of RA receptors, resulting in abnormalities in the eye, cerebral hemispheres, and the rhombencephalic neural tube (Lohnes et al., 1994). Significant progress has been made in understanding the mechanism by which RA regulates the organization of the early posterior hindbrain (Dupe et al., 1999; Nieder- 
(a)

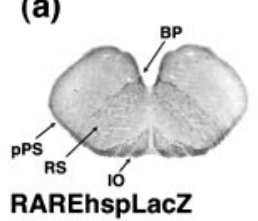

(b)

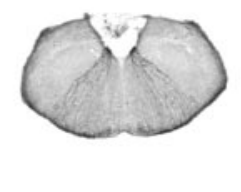

(c)
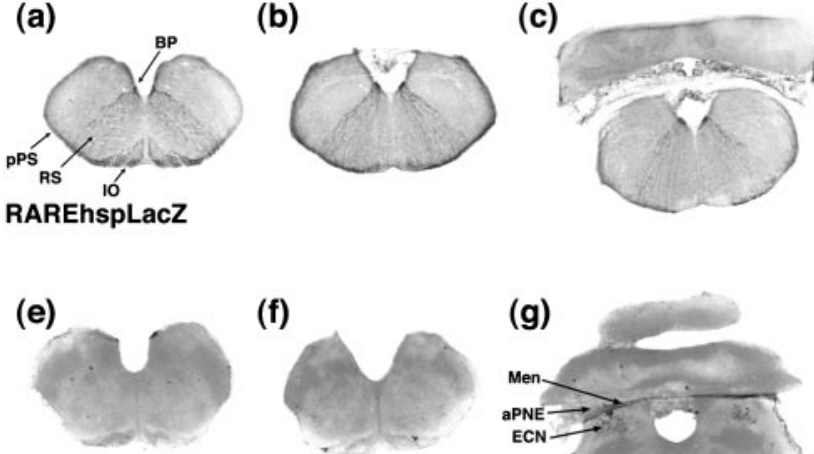

RALDH2

(i)

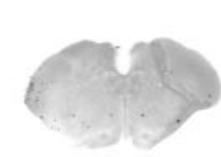

CYP26B1 (f)

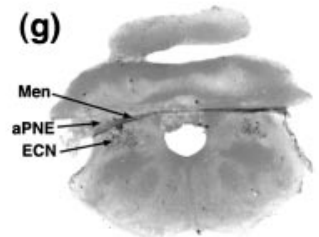

(k)

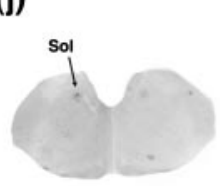

CYPB1

Figure 8. Comparison of RAREhsplacZ, RALDH2, and CYP26B1 in the E17 hindbrain withoutmeninges. RAREhsplacZ ( $a-d)$ continues to be in the peripheries of the hindbrain in the posterior precerebellar stream (pPS), which merges into the ventral aspects of the inferior olive (I0) as well as the anterior precerebellar stream (aPS). The basal plate (BP) and radial stream (RS) also remain positive. RALDH2 $(e-h)$ is present in meninges (Men) trapped between the precerebellar neuroepithelium (aPNE) and medulla and is also in the external cuneate nucleus (ECN). CYP26B1 ( $i-l)$ is in the ventricular layer (VL) of the cerebellum where it is also expressed in the Purkinje cell layer (PC). In the medulla (YP26B1 is in the ventricular layer of the alar plate (AP) and basal plate (BP), the solitary nucleus (Sol), the dorsal motor nucleus of the vagus (N10n), and adjacent to the nucleus of the facial nerve (N7n*). Scale bar, $1 \mathrm{~mm}$.

reither et al., 2000; Dupe and Lumsden, 2001), and RALDH2 in the paraxial mesoderm of the trunk has been considered the singular source of RA for the posterior hindbrain. In this study, however, it is shown that during a later period of development meningeal RALDH2 is present along the dorsal surface of the hindbrain extending to anterior locations. The distribution of RA-synthesizing and catabolic enzymes is shown to contribute to patterning of RA in the developing hindbrain, as suggested by the distribution of a RA reporter transgene.

The general concept that the balance of synthetic and catabolic enzymes determines the active concentration of RA in the embryo has been implied in a number of studies (McCaffery et al., 1999; Swindell et al., 1999; Abu-Abed et al., 2003; Deng et al., 2003). In the embryo, three RALDHs are known to exist, RALDH1, 2, and 3 (McCaffery and Drager, 2000) and two catabolic enzymes CYP26A1 (White et al., 1997) and CYP26B1 (MacLean et al., 2001) are present. Of the latter, CYP26B1 is the predominant catabolic enzyme in the hindbrain (Abu-Abed et al., 2002). Of the synthetic enzymes, RALDH1, the least specific of the RALDHs, is not expressed in the hindbrain. Likewise, RALDH3, which tends to be expressed in sensory neuroepithelia (Grun et al., 2000; Li et al., 2000), is absent, and the RA for the anterior hindbrain is derived from a paracrine source, RALDH2, in the hindbrain meninges.

The meninges start to condense from the mesenchyme surrounding the brain at E12.5, initially forming two layers: the outer dura mater and the inner leptomeninges (which will eventually form the arachnoid and the pia mater) (Kaufman and Bard, 1999). RALDH2 expression commences soon after the initial formation of the meninges. RA synthesis by RALDH2 from mesenchyme or mesenchymal derivatives guides development in

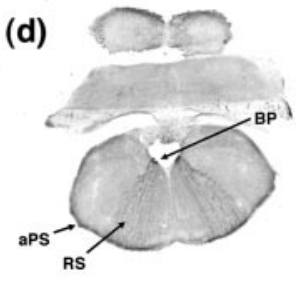

several embryonic tissues. RA sources include the anterior somites, which are derived from paraxial mesenchyme and provide RA for the early posterior rhombomeres, mesenchyme in the developing mouse inner ear (Romand et al., 2001), and limb mesenchyme where RA may be involved in cartilage development and skeletal muscle differentiation (Berggren et al., 2001). However, few studies have hitherto investigated the influence of the meninges on the developing brain. Sievers et al. (1985), Sievers and Pehlemann (1986), and Hartmann et al. (1998) have shown that meningeal cells can influence the development of neurons from the cerebellum and hippocampus, whereas Sensenbrenner et al. (1994) have demonstrated that meningeal cells influence the proliferation and maturation of neuroblasts. The meninges presumably influence the brain via the synthesis of growth factors such as TGF $\beta$, IGFII, and BMP-6 and -7 (Pelton et al., 1990; Sullivan and Feldman, 1994; Charytoniuk et al., 2000). RA can also be added to this list in its role as a transcriptional regulator that can itself induce expression of many growth factors (Braunhut et al., 1989; Glick et al., 1989; Lowe et al., 1992; Matsumoto et al., 1992) as well as growth factor and neurotrophin receptors (Joh et al., 1992; Kaplan et al., 1993; Afink et al., 1995; Wan et al., 1995; Xie et al., 1997; Sizemore et al., 1998; Yoshizawa et al., 1998).

It may be expected that a meningeal synthesized "growth factor regulator" such as RA would be synthesized throughout the meninges, which is often considered a homogenous tissue. RALDH2, however, is distinctive in that it is present at higher levels in the dorsal meninges than in the ventral. It has not been considered that the meninges might pattern the brain, but the concentration of RALDH2 in the dorsal meninges would result in a dorsal-ventral disparity in RA concentration. To determine whether the dorsal concentration of RALDH2 is manifest in the form of patterned RA signaling, we used a RAREhsplacZ RA reporter mouse to indicate whether RA signaling was localized. The reporter gene is based on the DR5 type RARE, the most frequently occurring RA response element (Mangelsdorf et al., 1994). It cannot be discounted that another, unknown, regulatory element may influence its expression; however, this reporter animal has been used extensively to map regions of RA signaling (Rossant et al., 1991; Moss et al., 1998; Wagner et al., 2000; Sakai et al., 2001) and gives a good representation of the known regions of RA signaling. When this transgene has been crossed into another mouse strain (B6/D2 hybrid), the pattern is unchanged (Wagner et al., 2000).

\section{The RA-synthesizing enzyme RALDH2 in the meninges}

The neural progenitors migrating away from the precerebellar neuroepithelium strongly express RAREhspLacZ but do not, themselves, express RALDH2. They do, however, migrate directly under a rich supply of RA in the form of the meninges, which highly express RALDH2. As a potent neural differentiation agent (McCaffery and Drager, 2000; Maden, 2002) RA may act to further promote their 

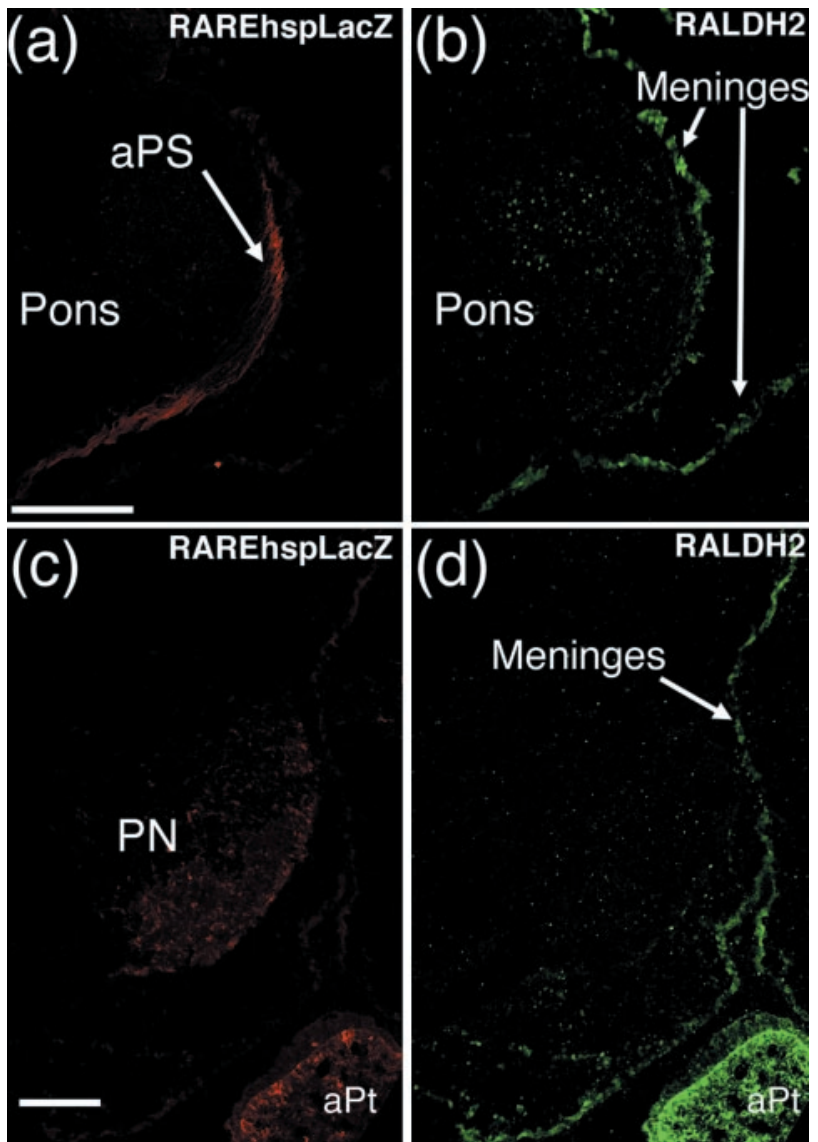

Figure 9. Relative distribution of RAREhsplacZ and RALDH2 in the anterior precerebellar stream and pontine nuclei. The RAREhsplacZ-positive cells of the anterior precerebellar stream (aPS) in coronal section (a) migrate directly under the RALDH2-positive meninges and mesenchyme $(b)$ when double labeled by immunohistochemistry of coronal sections at E16 (some meningeal detachment has occurred during sectioning). RAREhsplacZ at the pontine flexure of the E17 hindbrain in sagittal section ( $c$ ) shows expression in the pontine nuclei and the anterior pituitary (aPt) and RALDH 2 is present in the surrounding meninges and strongly in the anterior pituitary (d). Scale bar, $200 \mu \mathrm{m}$.

development. The neural progenitors from the anterior precerebellar neuroepithelium that form the pontine nuclei neurons continue their contact with RA at the pontine flexure, given that RALDH2 is also present in the ventral meninges, albeit more weakly than in the dorsal. The neural progenitors born in the precerebellar neuroepithelium that give rise to the pontine neurons strongly express $C R A B P I$. The function of CRABPI is uncertain; initial reports suggested that this binding protein promoted RA catabolism (Boylan and Gudas, 1992), but recent evidence has indicated that CRABPI can be transported into the nucleus, suggesting a role of this binding protein to import RA to the site of transcription (Gaub et al., 1998). The circumferentially migrating cells are not the only neurons expressing CRABPI in the hindbrain; for instance, the fastigial neurons of the cerebellum also express this binding protein (Parenti et al., 2002). The precursors of the neurons of these deep cerebellar nuclei derive from the ventrolateral neuroepithelium and take a circuitous route to the deep cerebellum, first migrating dorsome-

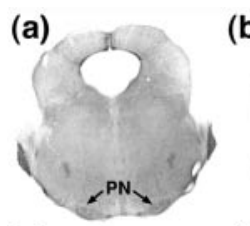

(g)

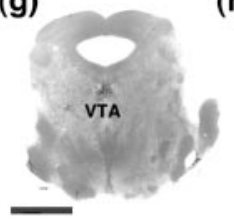

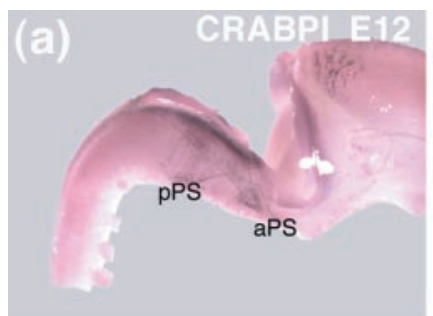
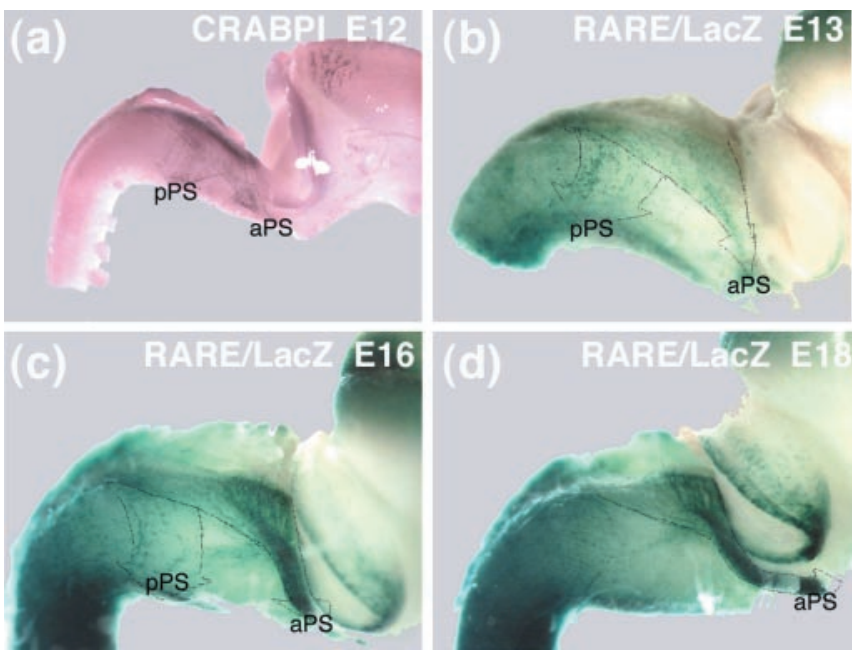

Figure 11. Comparison of CRABPI and RAREhspLacZ in migrating neurons in the developing hindbrain. CRABPI-positive cellsatE12 (a) are evident in two groups over the surface of the brain that likely represent the two migratory streams from the precerebellar neuroepithelium that migrate under the meninges. These two streams are outlined by broken lines and are labeled anterior precerebellar stream (aPS) and posterior precerebellar stream (pPS). A similar set of cells are RAREhspLacZ-positive atE13 and are outlined as aPS and pPS streams (b).AtE13, cells migrating to the pontine nuclei appear to derive from both anterior and posterior precerebellar neuroepithelium that blend together to form the anterior precerebellar stream. By E16 $(c)$, the anterior stream predominantly derives from the anterior precerebellar neuroepithelium and the posterior precerebellar neuroepithelium has diminished, and this is further accentuated by E18 ( $d$ ).

dially before descending ventrally. It is possible that RA synthesized by the cerebellar meninges plays a role in the initial migratory steps.

The second region of strong RAREhspLacZ expression is the basal plate of the fourth ventricle. Although this does not lie beneath the meninges, RALDH2-positive meninges overlies the thin vellum that covers the fourth ventricle. It is probable that RA will diffuse and enter the fourth ventricle, reaching the RAREhsplacZ-positive cells along the basal plate. Supporting the premise that RA is released into the ventricle is the intense expression of CYP26B1 in the anterior ventricular wall, presumably present to block the action of RA in most of this region. CYP26B1 is expressed at relatively low levels in the basal plate at E13 and is absent from this region by E15, allowing ventricular RA to still activate RAREhsplacZ in the basal plate.

The third region of RAREhspLacZ expression is the inferior olive. The progenitors for this precerebellar nucleus, which are not (b)

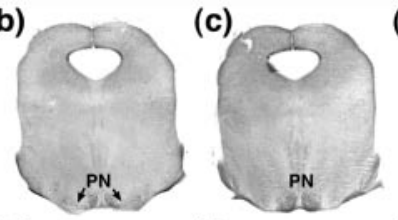

(h)

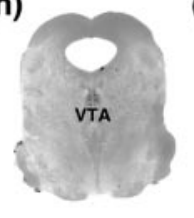

(i)

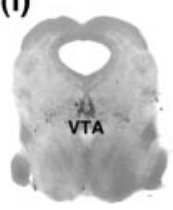

(d)

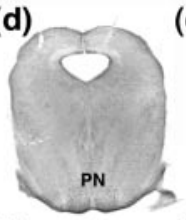

(j)

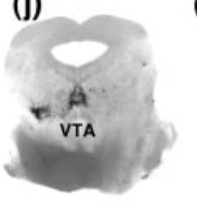

(e)

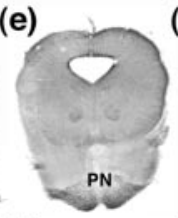

(k)

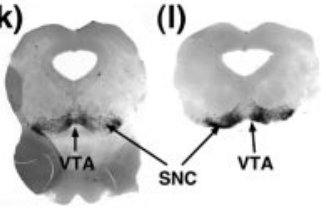

Figure 10. Relative distribution of RAREhsplacZ and RALDH1 in the boundary between the pons and midbrain. Serial $100 \mu \mathrm{m}$ vibratome sections labeled by immunohistochemistry for RAREhsplacZ $(a-f)$ and by in situ hybridization for RALDH1 ( $g-l)$ aligning the approximate corresponding section for the two probes with the most caudal section on the left. RAREhsplacZ in the pontine nuclei (PN) $(a-e)$ is distant and unlikely to be induced by RA synthesized by RALDH1 $(g-l)$ in the dopamine cell bodies of the ventral tegmental area (VTA) and substantia nigra compacta (SNC), although there is weak expression of RAREhspLacZ in the vicinity of the RALDH1-positive cells ( $f$ ). Scale bar, $1 \mathrm{~mm}$. 

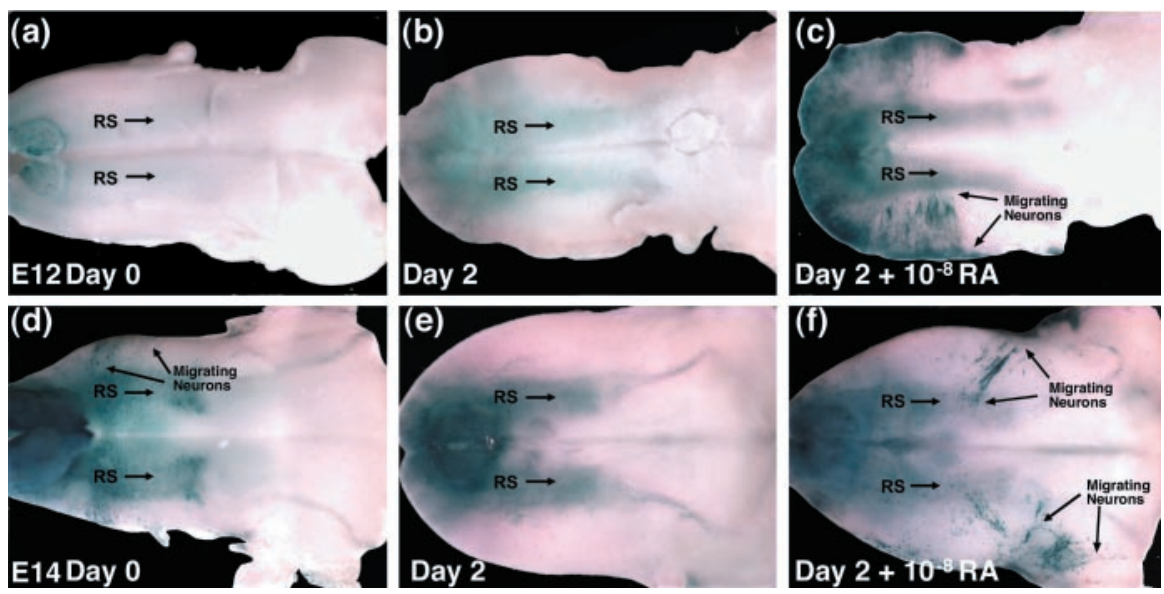

Figure 12. Absence of RAREhsplacZ expression in ventral migrating neurons when the meninges are removed and its expression when RA is replaced. Either E12 $(a-c)$ or E14 hindbrains $(e-g)$ with the meninges removed were cultured for $2 \mathrm{~d}$ on transwells, ventral side up. The E12 ventral hindbrain shows no lacZ staining neurons at day $0(a)$ or after $2 \mathrm{~d}$ of culture $(b)$, and the radial stream (RS) of RAREhsplacZ-positive cells is weak. However, strong RAREhsplacZ expression is evident when cultured in $10 \mathrm{~nm}$ RA (arrows, c), and cells in the radial stream are also induced. The E14 hindbrain already has RAREhsplacZ-positive neurons migrating over the caudal medulla at $0 \mathrm{~d}$ of culture (arrows, $d$ ). These are lost after $2 \mathrm{~d}$ of incubation $(e)$, but RAREhsplacZ cells are seen over the rostral ventral hindbrain when incubated with $10 \mathrm{~nm}$ RA (arrows, $f$ ). RAREhsplacZ in cells in the radial stream are already induced at day $0(a)$ and are no more intense after RA exposure $(f)$.

RAREhspLacZ-positive, do not migrate under the meninges but rather travel deeper within the brain (Altman and Bayer, 1987). Their initial time of birth at E10-11 is before the meninges develops; thus, the early progenitors are not exposed to RA. Once the progenitors have reached their ventral position, however, they lie under RALDH2-positive meninges presentover the posterior ventral medulla (Fig. 2d,f). This induces RAREhspLacZ in the inferior olive closest to the ventral surface. Furthermore, some of the RAREhspLacZ-positive neurons migrating around the posterior hindbrain at E15 and E17 (Figs. $7 b, 8 a$ ) appear to migrate into the ventral aspects of the inferior olive, suggesting that some of these cells may derive from this source of circumferentially migrating neurons.

In summary, the patterning of the RA-synthesizing enzyme RALDH2, as well as the localization of the RA response, revealed by RAREhsplacZ expression, implies that RA signaling in the hindbrain occurs predominantly around the peripheries of the hindbrain. A major site of its action is on the precerebellar neurons migrating around the hindbrain circumference that form the pontine nuclei. In contrast, the enzyme that degrades RA, CYP26B1, is expressed in subregions of the ventricular wall, as well as deeper regions of the hindbrain in and around developing nuclei presumably to "protect" those regions from the influence of RA.

\section{References}

Abu-Abed S, Dolle P, Metzger D, Beckett B, Chambon P, Petkovich M (2001) The retinoic acid-metabolizing enzyme, CYP26A1, is essential for normal hindbrain patterning, vertebral identity, and development of posterior structures. Genes Dev 15:226-240.

Abu-Abed S, MacLean G, Fraulob V, Chambon P, Petkovich M, Dolle P (2002) Differential expression of the retinoic acid-metabolizing enzymes CYP26A1 and CYP26B1 during murine organogenesis. Mech Dev 110:173-177.

Abu-Abed S, Dolle P, Metzger D, Wood C, MacLean G, Chambon P, Petkovich M (2003) Developing with lethal RA levels: genetic ablation of RAR gamma can restore the viability of mice lacking Cyp26A1. Development 130:1449-1459.

Afink GB, Nister M, Stassen BH, Joosten PH, Rademakers PJ, BongcamRudloff E, Van Zoelen EJ, Mosselman S (1995) Molecular cloning and functional characterization of the human platelet- derived growth factor alpha receptor gene promoter. Oncogene 10:1667-1672.

Altman J, Bayer SA (1987) Development of the precerebellar nuclei in the rat: I.-IV. J Comp Neurol 257:477-552.

Altman S, Bayer SA (1997) Development of the cerebellar system in relation to its evolution, structure, and functions. Boca Raton, FL: CRC.

Berggren K, McCaffery P, Drager U, Forehand CJ (1999) Differential distribution of retinoic acid synthesis in the chicken embryo as determined by immunolocalization of the retinoic acid synthetic enzyme, RALDH-2. Dev Biol 210:288-304

Berggren K, Ezerman EB, McCaffery P, Forehand CJ (2001) Expression and regulation of the retinoic acid synthetic enzyme RALDH-2 in the embryonic chicken wing. Dev Dyn 222:1-16.

Boylan JF, Gudas LJ (1992) The level of CRABP-I expression influences the amounts and types of all-trans-retinoic acid metabolites in F9 teratocarcinoma stem cells. J Biol Chem 267:21486-21491.

Braunhut SJ, Gudas LJ, Kurokawa T, Sasse J, D’Amore PA (1989) Expression of fibroblast growth factor by F9 teratocarcinoma cells as a function of differentiation. J Cell Biol 108:2467-2476.

Charytoniuk DA, Traiffort E, Pinard E, Issertial O, Seylaz J, Ruat M (2000) Distribution of bone morphogenetic protein and bone morphogenetic protein receptor transcripts in the rodent nervous system and up- regulation of bone morphogenetic protein receptor type II in hippocampal dentate gyrus in a rat model of global cerebral ischemia. Neuroscience 100:33-43.

de Diego I, Kyriakopoulou K, Karagogeos D, Wassef M (2002) Multiple influences on the migration of precerebellar neurons in the caudal medulla. Development 129:297-306.

Dellovade TL, Young M, Ross EP, Henderson R, Caron K, Parker K, Tobet SA (2000) Disruption of the gene encoding SF-1 alters the distribution of hypothalamic neuronal phenotypes. J Comp Neurol 423:579-589.

Deng L, Shipley GL, Loose-Mitchell DS, Stancel GM, Broaddus R, Pickar JH, Davies PJ (2003) Coordinate regulation of the production and signaling of retinoic acid by estrogen in the human endometrium. J Clin Endocrinol Metab 88:2157-2163.

Dollé P, Ruberte E, Leroy P, Morriss-Kay G, Chambon P (1990) Retinoic acid receptors and cellular retinoid binding proteins. I. A systematic study of their differential pattern of transcription during mouse organogenesis. Development 110:1133-1151.

Dollé P, Fraulob V, Kastner P, Chambon P (1994) Developmental expression of murine retinoid X receptor (RXR) genes. Mech Dev 45:91-104.

Dräger UC, McCaffery P (1994) Retinoic acid synthesis in the developing spinal cord. In: Enzymology and molecular biology of carbonyl metabolism, Vol V (Weiner H, Crabb DW, Flynn TG, eds), pp 185-192. New York: Plenum.

Dupe V, Lumsden A (2001) Hindbrain patterning involves graded responses to retinoic acid signalling. Development 128:2199-2208.

Dupe V, Ghyselinck NB, Wendling O, Chambon P, Mark M (1999) Key roles of retinoic acid receptors alpha and beta in the patterning of the caudal hindbrain, pharyngeal arches and otocyst in the mouse. Development 126:5051-5059.

Fujii H, Sato T, Kaneko S, Gotoh O, Fujii-Kuriyama Y, Osawa K, Kato S, Hamada H (1997) Metabolic inactivation of retinoic acid by a novel P450 differentially expressed in developing mouse embryos. EMBO J 16:4163-4173.

Gaub MP, Lutz Y, Ghyselinck NB, Scheuer I, Pfister V, Chambon P, RochetteEgly C (1998) Nuclear detection of cellular retinoic acid binding proteins I and II with new antibodies. J Histochem Cytochem 46:1103-1111.

Gavalas A, Krumlauf R (2000) Retinoid signalling and hindbrain patterning. Curr Opin Genet Dev 10:380-386.

Glick AB, Flanders KC, Danielpour D, Yuspa SH, Sporn MB (1989) Retinoic acid induces transforming growth factor-beta- 2 in cultured keratinocytes and mouse epidermis. Cell Regul 1:87-97. 
Grun F, Hirose Y, Kawauchi S, Ogura T, Umesono K (2000) Aldehyde dehydrogenase 6 , a cytosolic retinaldehyde dehydrogenase prominently expressed in sensory neuroepithelia during development. J Biol Chem 275:41210-41218.

Guthrie S (1996) Patterning the hindbrain. Curr Opin Neurobiol 6:41-48.

Hartmann D, Schulze M, Sievers J (1998) Meningeal cells stimulate and direct the migration of cerebellar external granule cells in vitro. J Neurocytol 27:395-409.

Joh T, Darland T, Samuels M, Wu JX, Adamson ED (1992) Regulation of epidermal growth factor receptor gene expression in murine embryonal carcinoma cells. Cell Growth Differ 3:315-325.

Kaplan DR, Matsumoto K, Lucarelli E, Thiele CJ (1993) Induction of TrkB by retinoic acid mediates biologic responsiveness to BDNF and differentiation of human neuroblastoma cells. Neuron 11:321-331.

Kaufman MH, Bard JBL (1999) The anatomical basis of mouse development. San Diego: Academic.

Lammer EJ, Armstrong DL (1992) Malformations of hindbrain structures among humans exposed to isotretinoin (13-cis-retinoic acid) during early embryogenesis. In: Retinoids in normal development and teratogenesis (Morris-Kay GM, ed), pp 281-295. Oxford: Oxford UP.

Li H, Wagner E, McCaffery P, Smith D, Andreadis A, Drager UC (2000) A retinoic acid synthesizing enzyme in ventral retina and telencephalon of the embryonic mouse. Mech Dev 95:283-289.

Lohnes D, Mark M, Mendelsohn C, Dollé P, Dierich A, Gorry P, Gansmuller A, Chambon P (1994) Function of the retinoic acid receptors (RAR) during development. (1) Craniofacial and skeletal abnormalities in RAR double mutants. Development 120:2723-2748.

Lowe WLJ, Meyer T, Karpen CW, Lorentzen LR (1992) Regulation of insulin-like growth factor I production in rat C6 glioma cells: possible role as an autocrine/paracrine growth factor. Endocrinology 130:2683-2691.

MacLean G, Abu-Abed S, Dolle P, Tahayato A, Chambon P, Petkovich M (2001) Cloning of a novel retinoic-acid metabolizing cytochrome P450, Cyp26B1, and comparative expression analysis with Cyp26A1 during early murine development. Mech Dev 107:195-201.

Maden M (1999) Heads or tails? Retinoic acid will decide. Bioessays 21:809-812.

Maden M (2002) Retinoid signalling in the development of the central nervous system. Nat Rev Neurosci 3:843-853.

Maden M, Horton C, Graham A, Leonard L, Pizzey J, Siegenthaler G, Lumsden A, Eriksson U (1992) Domains of cellular retinoic acid-binding protein I (CRABP I) expression in the hindbrain and neural crest of the mouse embryo. Mech Dev 37:13-23.

Mangelsdorf DJ, Umesono K, Evans RM (1994) The retinoid receptors. In: The retinoids: biology, chemistry, and medicine (Sporn MB, Roberts $\mathrm{AB}$, Goodman DS, eds), pp 319-350. New York: Raven.

Marin F, Puelles L (1995) Morphological fate of rhombomeres in quail/chick chimeras: a segmental analysis of hindbrain nuclei. Eur J Neurosci 7:1714-1738.

Matsumoto K, Gaetano C, Daughaday WH, Thiele CJ (1992) Retinoic acid regulates insulin-like growth factor II expression in a neuroblastoma cell line. Endocrinology 130:3669-3676.

McCaffery P, Dräger UC (1994a) Hotspots of retinoic acid synthesis in the developing spinal cord. Proc Natl Acad Sci USA 91:7194-7197.

McCaffery P, Dräger UC (1994b) High levels of a retinoic-acid generating dehydrogenase in the meso-telencephalic dopamine system. Proc Natl Acad Sci USA 91:7772-7776.

McCaffery P, Drager UC (1995) Retinoic acid synthesizing enzymes in the embryonic and adult vertebrate. Adv Exp Med Biol 372:173-183.

McCaffery P, Drager UC (2000) Regulation of retinoic acid signaling in the embryonic nervous system: a master differentiation factor. Cytokine Growth Factor Rev 11:233-249.

McCaffery P, Lee M-O, Wagner MA, Sladek NE, Dräger UC (1992) Asymmetrical retinoic acid synthesis in the dorso-ventral axis of the retina. Development 115:371-382.

McCaffery P, Wagner E, O’Neil J, Petkovich M, Drager UC (1999) Dorsal and ventral retinoic territories defined by retinoic acid synthesis, breakdown and nuclear receptor expression. Mech Dev 85:203-214.

Moss JB, Xavier-Neto J, Shapiro MD, Nayeem SM, McCaffery P, Drager UC, Rosenthal N (1998) Dynamic patterns of retinoic acid synthesis and response in the developing mammalian heart. Dev Biol 199:55-71.

Niederreither K, McCaffery P, Drager UC, Chambon P, Dolle P (1997) Restricted expression and retinoic acid-induced downregulation of the retinaldehyde dehydrogenase type 2 (RALDH-2) gene during mouse development. Mech Dev 62:67-78.
Niederreither K, Vermot J, Schuhbaur B, Chambon P, Dolle P (2000) Retinoic acid synthesis and hindbrain patterning in the mouse embryo. Development 127:75-85.

Parenti R, Wassef M, Cicirata F (2002) Expression of CRABP I mRNA in fastigial cells of the developing cerebellum. Eur J Neurosci 15:211-215.

Pelton RW, Dickinson ME, Moses HL, Hogan BL (1990) In situ hybridization analysis of TGF beta 3 RNA expression during mouse development: comparative studies with TGF beta 1 and beta 2. Development 110:609-620.

Romand R, Albuisson E, Niederreither K, Fraulob V, Chambon P, Dolle P (2001) Specific expression of the retinoic acid-synthesizing enzyme RALDH2 during mouse inner ear development. Mech Dev 106:185-189.

Rossant J, Zirngibl R, Cado D, Shago M, Giguère V (1991) Expression of a retinoic acid response element-hsplacZ transgene defines specific domains of transcriptional activity during mouse embryogenesis. Genes Dev 5:1333-1344.

Ruberte E, Friederich V, Chambon P, Morriss-Kay G (1993) Retinoic acid receptors and cellular retinoid binding proteins. III. Their differential transcript distribution during mouse nervous system development. Development 118:267-282.

Sakai Y, Meno C, Fujii H, Nishino J, Shiratori H, Saijoh Y, Rossant J, Hamada H (2001) The retinoic acid-inactivating enzyme CYP26 is essential for establishing an uneven distribution of retinoic acid along the anterioposterior axis within the mouse embryo. Genes Dev 15:213-225.

Sensenbrenner M, Deloulme JC, Gensburger C (1994) Proliferation of neuronal precursor cells from the central nervous system in culture. Rev Neurosci 5:43-53.

Sievers J, Pehlemann FW (1986) Influences of meningeal cells on brain development. Findings and hypothesis. Naturwissenschaften 73:188-194.

Sievers J, Pehlemann FW, Baumgarten HG, Berry M (1985) Selective destruction of meningeal cells by 6-hydroxydopamine: a tool to study meningealneuroepithelial interaction in brain development. Dev Biol 110:127-135.

Sizemore N, Choo CK, Eckert RL, Rorke EA (1998) Transcriptional regulation of the EGF receptor promoter by HPV16 and retinoic acid in human ectocervical epithelial cells. Exp Cell Res 244:349-356.

Smith D, Wagner E, Koul O, McCaffery P, Drager UC (2001) Retinoic acid synthesis for the developing telencephalon. Cereb Cortex 11:894-905.

Sockanathan S, Jessell TM (1998) Motor neuron-derived retinoid signaling specifies the subtype identity of spinal motor neurons. Cell 94:503-514.

Sullivan KA, Feldman EL (1994) Immunohistochemical localization of insulin-like growth factor-II (IGF-II) and IGF-binding protein-2 during development in the rat brain. Endocrinology 135:540-547.

Swindell EC, Thaller C, Sockanathan S, Petkovich M, Jessell TM, Eichele G (1999) Complementary domains of retinoic acid production and degradation in the early chick embryo. Dev Biol 216:282-296.

Theiler K (1972) The house mouse. Development and normal stages from fertilization to 4 weeks of age. New York: Springer.

Vaessen MJ, Kootwijk E, Mummery C, Hilkens J, Bootsma D, van Kessel AG (1989) Preferential expression of cellular retinoic acid binding protein in a subpopulation of neural cells in the developing mouse embryo. Differentiation 40:99-105.

Wagner E, McCaffery P, Drager UC (2000) Retinoic acid in the formation of the dorsoventral retina and its central projections. Dev Biol 222:460-470.

Wagner M, Han B, Jessell TM (1992) Regional differences in retinoid release from embryonic neural tissue detected by an in vitro reporter assay. Development 116:55-66.

Wan YJ, Wang L, Wu TC (1995) Retinoic acid induces activin receptor IIB mRNA in F9 embryonal carcinoma cells. J Mol Endocrinol 14:247-254.

White J, Beckett-Jones B, Guo Y, Dilworth F, Bonasoro J, Jones G, Petkovich M (1997) cDNA cloning of human retinoic acid-metabolizing enzyme (hP450RAI) identifies a novel family of cytochromes P450. J Biol Chem 272:18538-18541.

White JA, Guo YD, Baetz K, Beckett-Jones B, Bonasoro J, Hsu KE, Dilworth FJ, Jones G, Petkovich M (1996) Identification of the retinoic acid-inducible all-trans-retinoic acid 4-hydroxylase. J Biol Chem 271:29922-29927.

Wingate RJ (2001) The rhombic lip and early cerebellar development. Curr Opin Neurobiol 11:82-88.

Xie P, Cheung WM, Ip FC, Ip NY, Leung MF (1997) Induction of TrkA receptor by retinoic acid in leukaemia cell lines. NeuroReport 8:1067-1070.

Yoshizawa M, Miyazaki H, Kojima S (1998) Retinoids potentiate transforming growth factor-beta activity in bovine endothelial cells through up-regulating the expression of transforming growth factor-beta receptors. J Cell Physiol 176:565-573. 